\title{
COVID-19 y bioética global
}

\section{COVID-19 and global bioethics}

\author{
Henk ten Have* \\ https://doi.org/10.36105/mye.2022v33n1.01
}

\section{Resumen}

El fenómeno global de la pandemia ha reactivado la noción de bioética global, argumentando que la bioética convencional no aborda suficientemente la experiencia pandémica. Esta experiencia pone de relieve la conectividad, la vulnerabilidad diferencial, lo inesperado y la falta de preparación. Durante la pandemia, las preocupaciones éticas se enfocan de una manera específica. Este artículo examina tres formas de enmarcarlas: con las nociones de excepcionalidad, controlabilidad y binaridad. A continuación se analiza el marco de la bioética global, que ofrece una perspectiva más amplia e inclusiva de la experiencia de la pandemia. Una noción fundamental en este marco es la relacionalidad. También acentúa que los intereses individuales y comunes no se oponen. Una tercera consideración en esta perspectiva es la solidaridad. Un marco global de bioética es un incentivo para repensar la globalización, la gobernanza global, la salud pública y la asistencia sanitaria. Si la bioética como esfuerzo social y global moviliza la imaginación moral para ampliar el alcance de la preocupación moral aplicando la capacidad humana de empatizar, contribuye de forma crucial a mejorar la vida social y la civilización.

\footnotetext{
* Universidad de Duquesne, Centro de Ética Sanitaria. Pittsburgh, EE.UU. Correo electrónico: henktenhave10@gmail.com https://orcid.org/0000-0002-3224-7943 Recepción: 15 de agosto de 2021. Aceptación: 12 de septiembre de 2021.
}

Medicina y Ética - Enero-Marzo 2022 - Vol. 33 - Núm. 1 https://doi.org/10.36105/mye.2022v33n1.01 
Palabras clave: bioética global, relacionalidad, solidaridad, pandemia, salud pública.

\section{COVID-19 y ética}

La pandemia de COVID-19 se asocia a un aumento de las publicaciones sobre ética y a un incremento del interés por la bioética mundial. Una búsqueda en PubMed (a principios de julio de 2021) muestra que la pandemia inspiró un gran número de publicaciones sobre cuestiones éticas relacionadas. Estas publicaciones abarcan una serie de cuestiones: normas de atención en caso de crisis, investigación acelerada, deber de atención, triaje en el tratamiento intensivo, priorización de la vacunación. La mayoría de los estudios se refieren a las dimensiones morales del tratamiento (Tabla 1).

Tabla 1: Número de publicaciones.

\begin{tabular}{|l|c|c|c|}
\hline Términos de búsqueda & $\mathbf{2 0 1 9}$ & $\mathbf{2 0 2 0}$ & $\begin{array}{c}\mathbf{2 0 2 1} \\
\text { (primera mitad) }\end{array}$ \\
\hline Ética y covID-19 & 3 & 2,2525 & 1,729 \\
\hline Ética, CovID-19 y tratamiento & & 1,419 & 802 \\
\hline Ética, CovID-19 y normas de atención & & 236 & 150 \\
\hline Ética, CovID-19 y triaje & & 188 & 100 \\
\hline Ética, COVID-19 y priorización & & 131 & 103 \\
\hline Ética, CovID-19 y deber de asistencia & & 41 & 32 \\
\hline
\end{tabular}

Un número significativo de estas publicaciones aborda explícitamente la bioética global. Si observamos la evolución de las publicaciones sobre bioética mundial en general, se observa que durante mucho tiempo el número es bastante bajo, pero desde 2014 empezó a aumentar (Tabla 2).

Fuente: Elaboración propia.

En 2020, una búsqueda con las palabras clave «COVID-19 \& global Bioethics» produjo 63 publicaciones, mientras que en el primer se- 
COVID-19 y bioética global

Tabla 2: Crecimiento de las publicaciones mundiales sobre bioética.

\begin{tabular}{|ll|}
\hline - desde 1982 & $1-2$ / año \\
\hline- desde 1999 & 28 / año \\
\hline - desde 2014 & 166 / año \\
\hline
\end{tabular}

Fuente: Elaboración propia.

mestre de 2021 se publicaron 60 artículos de revistas. Esto significa que en 2020, el 23\% de todas las publicaciones sobre bioética global estaban relacionadas con la pandemia de COVID-19 (63 de 236), y en la primera mitad de 2021 subió al 39\% (60 de 152). Si se observa el número total de publicaciones con la palabra clave «ética», la contribución de las publicaciones sobre COVID-19 y ética aumentó del 13\% en $2020(2,525$ de 19,850) al 16\% en el primer semestre de $2021(1,729$ de 10,569).

Una conclusión provisional es que la pandemia de COVID-19 ha estimulado las actividades de investigación y publicación centradas en las dimensiones éticas de la experiencia pandémica. Sin embargo, es interesante que una serie de publicaciones se dediquen a la autorreflexión bioética, argumentando que la bioética no está abordando suficientemente las cuestiones de la comunidad, el bien común, la solidaridad y la equidad. Mientras que la nueva amenaza vírica pone de manifiesto la vulnerabilidad y la interdependencia comunes, las políticas nacionalistas sólo se centran en las necesidades de países concretos, desviando a menudo los recursos de los países de ingresos bajos y medios (1). Aunque la pandemia agrava las disparidades sanitarias dentro de los países y en todo el mundo, en la corriente principal de la bioética las disparidades y desigualdades no han desempeñado un papel importante (2). Los análisis y las recomendaciones en materia de bioética suelen basarse en cálculos utilitarios, partiendo de la base de que el principal conflicto se da entre los intereses individuales y el bien común (3). Otro dilema que se menciona con frecuencia es el que existe entre la salud

Medicina y Ética - Enero-Marzo 2022 - Vol. 33 - Núm. 1 
pública y la libertad individual (4). Estos análisis autorreflexivos concluyen que el enfoque dominante de la bioética es inadecuado frente a la pandemia, por su falta de orientación normativa coherente (5) o por su excesivo énfasis en la autonomía personal y el individualismo $(6,7)$. La pandemia ha puesto de manifiesto las deficiencias y los conceptos erróneos de la bioética (8). Otros argumentan con fuerza que la bioética pos-COVID debe tener una perspectiva global (9). Debería prestarse más atención a la integración y la conexión; es decir, no sólo al contexto más amplio de la asistencia sanitaria, sino también a las redes sociales y culturales en las que se incluyen los individuos. Esto significa articular la importancia del bien común y las perspectivas de justicia, vulnerabilidad y solidaridad. En la era del COVID-19, la bioética global debe replantearse para abordar los fenómenos globales, de modo que surja un nuevo panorama de gobernanza sanitaria mundial (10), se examinen las condiciones de la solidaridad y la cooperación globales (11) y se incluyan las voces de las poblaciones marginadas y desfavorecidas en el discurso ético (12). Si una amenaza de enfermedad global como el COVID-19 exige respuestas globales, se necesita un marco ético más amplio y abarcador que el proporcionado por el modelo dominante de bioética (13).

\section{La experiencia de la pandemia}

Una de las razones por las que el fenómeno de la pandemia reactiva la noción de bioética global está relacionada con las características de la experiencia pandémica. Para muchas personas, especialmente en países de altos ingresos, la globalización ha sido un proceso más bien abstracto y externo, que ha dado lugar a productos útiles y menos costosos, como teléfonos inteligentes, computadoras y ropa, pedidos en línea a través de Amazon, Google y Apple, así como a la posibilidad de viajar y tener vacaciones en cualquier lugar del planeta. La amenaza del COVID-19 ha sacado a los fenóme- 
nos globales de su abstracción beneficiosa. La globalización se ha convertido ahora en una experiencia interna, que afecta a la propia vida humana. Se convierte en una fuente de tensión entre países y regiones, y en un impedimento para las medidas de salud pública, manifestando dependencias y desigualdades. La experiencia de la pandemia pone, así, de manifiesto la conectividad como característica básica de la globalización. Una dimensión de la bioética global es su alcance mundial o planetario. Este significado se desprende de la imagen de la Tierra que aparece en la portada del primer libro de Potter sobre bioética (14). El planeta se visualiza como un globo solitario en el espacio exterior, articulando la experiencia de que es el hogar común de los seres humanos dentro del universo. Esta imagen del globo, por poderosa que sea, plantea la Tierra como un objeto externo. No provoca la sensación de que, de hecho, es el hábitat de los seres humanos, de modo que nuestra relación con las condiciones «ambientales» es más bien interna que externa; no podemos desvincularnos de nuestro hábitat; nuestro mundo vital no puede desconectarse del planeta. Por tanto, la imagen del «globo» corre el riesgo de separar al ser humano del contexto en el que habita. Una metáfora más adecuada para expresar la característica de conectividad es la de «esfera» (15). El uso de esta metáfora evoca la interconexión, la relación y la interdependencia. Esto también se expresa en nociones como «atmósfera», «biosfera», «ecosfera»y «virósfera». El planeta no es sólo el lugar de residencia, sino el mundo en el que viven los seres humanos, en el que se sienten como en casa. Para los seres humanos, como incrustados en esferas, el medio ambiente no es un escenario externo sino parte de su mundo vital. La noción de esfera presenta el mundo como experiencia vivida, percibida y comprendida desde dentro. El mundo humano comienza en lo local y no en lo global, porque la visión esférica acentúa la incrustación y, por tanto, la localidad. En consecuencia, la globalización no es un proceso externo que repercute en nuestro globo común, sino que afecta al mundo humano, al mundus, ampliando el mundo de la vida a través de la interacción

Medicina y Ética - Enero-Marzo 2022 - Vol. 33 - Núm. 1

https://doi.org/10.36105/mye.2022v33n1.01 
global y la difusión cultural. Por ello, a veces se propone la mundialización como un término más adecuado para los procesos globales (16). La mundialización (tal como se expresa en los términos franceses «mondialisation» $\mathrm{y}$ «bioéthique mondiale») subraya el intercambio y la integración de ideas y valores de las personas y las culturas de todo el planeta, más que las dimensiones espaciales y geográficas del mundo como nuestro hogar.

La segunda característica de la experiencia pandémica es la vulnerabilidad diferencial. En principio, todos los seres humanos pueden infectarse, pero el SARS-CoV-2 no está afectando a todos de la misma manera y con la misma gravedad. Los ciudadanos de mayor edad, las personas con problemas de salud subyacentes y los grupos raciales y étnicos minoritarios tienen un mayor riesgo de enfermar, ser hospitalizados y morir a causa del COVID-19 (17). Los habitantes de los barrios pobres son más vulnerables a la enfermedad, mientras que se describen brotes recurrentes de COVID en residencias de ancianos, asilos y prisiones (18). Las poblaciones desfavorecidas suelen tener más problemas de salud como consecuencia de la falta de acceso a la asistencia sanitaria, condiciones de vida precaria e insegura, falta de empleo y degradación ambiental. Las personas con discapacidades y enfermedades crónicas y las personas mayores tienen afecciones que reducen la esperanza de vida en el largo plazo. Estas poblaciones y personas corren el riesgo de verse doblemente afectadas, no sólo por el virus, sino también por los criterios utilitarios de triaje, que tienen como objetivo maximizar el número de años de vida salvados, de modo que se niegue la prioridad en el tratamiento debido a su mal pronóstico en el largo plazo (19). Una de las áreas más perjudicadas de numerosas sociedades son las personas mayores y las residencias de ancianos, mientras que la formulación de políticas durante bastante tiempo se centra en la atención hospitalaria aguda, y hay poca protección disponible para los residentes mayores, frágiles y vulnerables de estos hogares. Además, las medidas de salud pública tienen efectos desiguales. Estas medidas, como los cierres y las pruebas a gran escala, se aplican en las 
zonas más ricas del mundo y se defienden para otros países, mientras que no se tiene en cuenta el contexto diferente de los países con menos recursos. Un número considerable de personas, sobre todo en los países en desarrollo, no pueden cumplir con las normas, porque viven junto a otras muchas personas en viviendas hacinadas, o carecen de una vivienda adecuada, con instalaciones sanitarias limitadas, poco acceso a la asistencia sanitaria y a Internet, no tienen empleos formales y tienen que salir a ganarse la vida, cuando no existen esfuerzos gubernamentales para proporcionar ayuda económica, ingresos seguros y seguro médico. Se supone que los países de bajos ingresos deben aplicar las mismas medidas de salud pública que los países más prósperos, pero no pueden adquirir suficientes equipos de protección, y no se les da prioridad en la distribución de recursos globales como kits de pruebas, medicamentos y vacunas. Pero incluso en los países con buenos recursos, las personas con trabajos de servicios mal pagados (como el comercio minorista, los servicios de alimentación, el cuidado de niños y la hostelería) deben seguir trabajando. Lo mismo ocurre con las personas de menor nivel socioeconómico, que tienen que trabajar en condiciones de hacinamiento (por ejemplo, en asilos), tienen que utilizar el transporte público y a menudo viven en hogares multigeneracionales. El encierro, el distanciamiento y el autoaislamiento son medidas que pueden llevar a cabo mejor los ciudadanos más ricos y los que disponen de un mejor alojamiento. Pero incluso en estas circunstancias, las cargas no se distribuyen de forma equitativa: las mujeres suelen verse más afectadas que los hombres cuando se cierran las escuelas y las guarderías, y dado que tienen más empleos de tiempo parcial, es más probable que se interrumpan. La evidencia de que el COVID-19 está agravando las desigualdades existentes en la salud y la sociedad señala la necesidad de prestar especial atención a las nociones de vulnerabilidad, solidaridad e igualdad para abordar las disparidades desde un marco ético más amplio (20). La pandemia también ha hecho vulnerables a algunas personas debido a la xenofobia, la búsqueda de chivos expiatorios,

Medicina y Ética - Enero-Marzo 2022 - Vol. 33 - Núm. 1

https://doi.org/10.36105/mye.2022v33n1.01 
la estigmatización y la discriminación. Que las experiencias no son iguales en todas partes y que el COVID-19 refuerza las desigualdades existentes se pone de manifiesto en la brecha global de las vacunas. Mientras que en muchos países del Norte Global casi el $50 \%$ de la población ha recibido al menos una dosis de la vacuna COVID-19, en los países de bajos ingresos esto sólo ocurre para el $1.1 \%$ de las personas (datos hasta el 21 de julio de 2021). El continente relativamente más afectado es América Latina. Con el 8\% de la población mundial, tiene el $20 \%$ de todos los casos globales de coronavirus, y el $32 \%$ de las muertes globales. Sólo el 10\% de la población está totalmente vacunada, pero en algunos países (por ejemplo, Honduras y Guatemala) es casi nula. En julio, casi todas las nuevas infecciones están causadas por la variante Lambda. Los casos aumentan rápidamente, incluso en Chile, donde más del 61\% de la población está totalmente vacunada. El continente tiene una capacidad limitada de vigilancia del genoma, por lo que la variante se detectó tarde, y es difícil estimar la prevalencia total de la variante Lambda. El gran reservorio de personas no vacunadas facilita la mutación del virus, volviéndose más infeccioso y haciendo que las vacunas sean menos efectivas. En la mayoría de los países de América Latina, la vacuna más utilizada es la china CoronaVac, que tiene una escasa eficacia. Un estudio reveló que una única dosis sólo tiene un 3\% de eficacia, que se eleva al 56,5\% después de las dos dosis (21).

La tercera característica de la experiencia pandémica es lo inesperado y la falta de preparación. No es la primera vez que la humanidad se enfrenta a enfermedades pandémicas. La vida humana siempre ha estado marcada por las infecciones, ya que humanos, animales y microbios cohabitan en el mismo mundo. Pero los avances de la ciencia médica han promovido la creencia de que estas enfermedades pueden ser manejadas y controladas, y a veces erradicadas mediante vacunas y medicamentos (especialmente en las primeras etapas de la vida). Las enfermedades infecciosas como amenazas letales se han vuelto menos temibles para muchas personas. Sin embargo, se 
trata de un prejuicio cultural, ya que las poblaciones de los países menos desarrollados están continuamente amenazadas por las enfermedades infecciosas. En 2019, justo antes del brote de COVID-19, 409,000 personas murieron de malaria y 1,4 millones de tuberculosis $(22 ; 23)$. De hecho, especialmente en África y Asia, hasta ahora hay más personas infectadas por la malaria (en 2019, 229 millones de casos) y por el dengue (390 millones de personas) que por el COVID-19 (24). Las pandemias letales anteriores, como la peste negra en el siglo XIV, el cólera en el siglo XIX y la denominada gripe española en el siglo XX, han tenido un gran impacto en la sociedad y la cultura, pero en su mayoría se consideraron historia. Enfermedades como la gripe aviar, el ébola y el zika han sido una alerta temprana para la pandemia actual, pero las lecciones no se han tomado en serio en la mayoría de los países. Para la mayoría de los países y autoridades, la amenaza vírica de COVID-19 fue una sorpresa. Un ejemplo es la lista de diez amenazas para la salud mundial que requieren atención para la próxima década, publicada por la Organización Mundial de la Salud a principios de 2019 (25). La contaminación del aire y el cambio climático encabezan la lista. También incluye enfermedades infecciosas como la gripe mundial, el ébola y otros patógenos de alta amenaza, el dengue y el VIH. La lista ha servido de base para el nuevo plan estratégico quinquenal de la Organización (el $13^{\circ}$ Programa General de Trabajo), que asigna tres mil millones de dólares estadounidenses para transformar el futuro de la salud pública, con el fin de garantizar un mayor acceso a la atención sanitaria, una mejor protección frente a las emergencias sanitarias y hacer que más personas experimenten una mejora de su salud y bienestar. La lista de 2019 difiere de la publicada un año antes. El número uno de esta lista de 2018 es la gripe pandémica. De hecho, la mayoría de las amenazas de esta lista son enfermedades infecciosas, como el cólera, la difteria, la malaria, la meningitis y la fiebre amarilla. Muchas de estas infecciones ya no se consideran amenazas mundiales un año después. Justo antes del brote de COVID-19 no se esperaba, obviamente, una amenaza de

Medicina y Ética - Enero-Marzo 2022 - Vol. 33 - Núm. 1 
pandemia inminente, aunque desde 1992 los expertos han advertido de los peligros de las enfermedades infecciosas emergentes. La experiencia con la pandemia de coronavirus devolvió a la humanidad a su condición de conexión. Aunque existen numerosas diferencias entre el pasado y el presente, hay dos realidades básicas que siguen siendo las mismas. Una es la realidad de los microorganismos, que nos recuerda que el ser humano está inmerso en la naturaleza. El ser humano no puede sobrevivir sin los virus. Constituyen una virósfera que no sólo rodea a los seres humanos, sino que está dentro de ellos (26). La otra realidad son los propios seres humanos. No está claro hasta qué punto su naturaleza y su comportamiento han cambiado fundamentalmente a lo largo del tiempo. Parece que, ante un desafío letal, los humanos siguen mostrando el mismo comportamiento que en épocas anteriores. Aunque ahora tengamos más conocimientos médicos que nunca, es necesario que los seres humanos los utilicen. Las recomendaciones de políticas sólo funcionan si se siguen e implementan. La información sanitaria nunca es completamente segura, por lo que siempre hay dudas e incertidumbres. También se aplica dentro de un contexto social y cultural que puede ser autoritario o liberal, por lo que se determinan los límites y las restricciones en cuanto a la aplicación o el cumplimiento de medidas estrictas como la cuarentena, el aislamiento o las pruebas. Como forma de drama, una pandemia no es sólo un acontecimiento médico, sino un fenómeno social con una evolución particular en el tiempo, que depende de cómo se comportan e interactúan los seres humanos. El conocimiento del patógeno y de la etiología de la enfermedad no es suficiente para controlar una enfermedad epidémica (27).

\section{Enmarcar las preocupaciones éticas}

La forma en que se conciben y se formulan las preocupaciones éticas es el resultado de una forma específica de encuadre. Por ejem- 
plo, el cuidado de pacientes infecciosos se interpreta como un deber profesional que deja de lado las consideraciones de riesgo personal o de riesgo para los miembros de la familia y parientes, pero también las responsabilidades de los centros de salud de proporcionar un entorno seguro. Otro ejemplo son las medidas de política, como el distanciamiento físico y el enmascaramiento, que a menudo pasan de apelaciones a la responsabilidad voluntaria a requisitos obligatorios con el argumento de que el interés colectivo prevalece sobre los intereses de las personas, enfatizando el cumplimiento de las medidas en lugar de la adhesión a ellas sobre la base de la persuasión y motivación. Un tercer ejemplo es el argumento de que en circunstancias de emergencia se debe dar prioridad al tratamiento de los pacientes con COVID, ya que eso salvará la mayoría de vidas, mientras que el tratamiento de pacientes con otras afecciones se reduce o cancela como «daño colateral» con tres nociones fundamentales: excepcionalidad, controlabilidad y binaridad.

\section{a) Excepcionalidad}

Las preocupaciones éticas durante la pandemia suelen estar preestructuradas y formateadas con el discurso de la excepcionalidad. Puede adoptar dos formas. La excepcionalidad intrínseca se refiere a la pretensión de estar fuera de la pauta general y, por tanto, especialmente privilegiada. Antes del COVID-19, algunos países se consideraban excepcionales porque suponían estar bien preparados para una epidemia mundial. Tras el brote de COVID-19, algunos países presumen de ser menos vulnerables y más resistentes que otros. Durante la pandemia, los países intentan perfilarse como excepcionales en sus enfoques políticos, contribuciones científicas o estrategias de vacunación. Los profesionales de la salud hacen reivindicaciones especiales exigiendo prioridad en el triaje y la vacunación, debido a los mayores riesgos asumidos y a su valor instrumental para el sistema sanitario. Desde el punto de vista ético, los argu-

Medicina y Ética - Enero-Marzo 2022 - Vol. 33 - Núm. 1

https://doi.org/10.36105/mye.2022v33n1.01 
mentos a favor de la excepcionalidad intrínseca pueden ser verdaderos o falsos, pero lo que hacen es asignar tal valor a un país o una profesión que resulta difícil criticar a los responsables políticos, a los científicos o a los trabajadores sanitarios porque son especiales. La segunda forma es la excepcionalidad extrínseca; es decir, el argumento de que una situación de emergencia crea condiciones especiales en las que ya no se aplican las normas y prácticas habituales. En esta forma, la propia perspectiva ética se ve afectada. Se argumenta que las circunstancias especiales justifican acciones que normalmente no serían aceptables, por ejemplo, el confinamiento de los ciudadanos en sus hogares, los mandatos de pruebas, las normas de atención de crisis, la agilización de la investigación científica o la 'despriorización' de los pacientes mayores para las intervenciones de ventilación. Supuestamente, como ilustran estos ejemplos, las consideraciones éticas que se aplican en circunstancias normales ya no pueden utilizarse, sino que deben obviarse o invertirse en un marco utilitario, para que el interés individual de los pacientes se subordine al interés común de todos. En el contexto de la salud pública, la excepcionalidad extrínseca se manifiesta, por ejemplo, en las normas de seguridad que se utilizan. La necesidad de lanzar pronto nuevas vacunas y su aprobación de uso urgente se asocia a una vigilancia de la seguridad y la eficacia menos rigurosa de lo habitual. Otro ejemplo es el debate sobre la reapertura de la sociedad y la economía. Mientras que en circunstancias normales se utilizarán todas las posibilidades para minimizar los riesgos potenciales, éste no ha sido el caso en las políticas de salud pública de la mayoría de los países, como lo demuestran las decisiones de relajar las medidas estrictas y reabrir la economía, no porque la amenaza vírica haya disminuido, sino porque la seguridad y la protección de la salud se equilibran con otros valores como la recuperación económica. Esto también es evidente en las primeras recomendaciones políticas de la OMS y de varios gobiernos de no utilizar mascarillas. Aunque las pruebas de su eficacia no son claras, en condiciones ordinarias el principio de precaución habría lle- 
vado a la política a aconsejar su uso. En la vida ordinaria, la seguridad es un principio básico que ha instigado muchas regulaciones para el tráfico humano, la producción industrial y las actividades ocupacionales. El hecho de que se consideren aceptables más riesgos en condiciones de emergencia queda ilustrado en el debate sobre los efectos adversos de algunas vacunas. Cuando en marzo de 2021 se identifican los graves efectos secundarios de la vacuna de AstraZeneca, muchos países pausan el despliegue de esta vacuna. Los expertos responden críticamente a la pausa y argumentan que la vacunación debe continuar porque los riesgos son extraordinariamente bajos (1 de cada 100,000). Pero estas garantías de que los efectos secundarios son raros, y mucho más bajos que el riesgo de enfermedad grave por infección, no son convincentes, ya que un simple cálculo de beneficio-daño a nivel poblacional no es suficiente a nivel individual. Las vacunas se administran a personas sanas y protegen contra una enfermedad que podría afectarles, pero no necesariamente. Los individuos no comparan el riesgo de efectos secundarios con la probabilidad de morir de COVID, sino con la probabilidad de infectarse. Esta última probabilidad está en sus propias manos y, si siguen meticulosamente las medidas de salud pública, asumen que el riesgo de infección es extremadamente bajo. El argumento de la excepcionalidad de que son aceptables más riesgos de seguridad durante una pandemia se aplica a las poblaciones, pero no funciona a nivel individual, donde los efectos secundarios están asociados a la situación personal de las personas. $\mathrm{El}$ argumento en sí mismo puede tener efectos negativos, ya que aumenta la experiencia de que los individuos pueden ser sacrificados por un bien mayor, y que los intereses de los individuos son despreciados, ya que en la guerra la velocidad es más importante que la precaución. El debate sobre la seguridad de las vacunas es un ejemplo de los inconvenientes de la excepcionalidad. Ilustra el impacto del pensamiento utilitario que promueve un enfoque calculador, impersonal, abstracto y descontextualizado, centrado únicamente en las consecuencias, sopesando los beneficios y los daños,

Medicina y Ética - Enero-Marzo 2022 - Vol. 33 - Núm. 1

https://doi.org/10.36105/mye.2022v33n1.01 
no para los individuos sino para las poblaciones, y despreciando otros principios éticos. También se asocia con un enfoque tecnocrático y paternalista, dando a los expertos (epidemiólogos, virólogos y especialistas en cuidados intensivos) la primera y última palabra en la toma de decisiones políticas. Esto se pone de manifiesto en el desarrollo y en la aplicación de los sistemas de triaje, así como en las estrategias de vacunación. Además, la excepcionalidad se aplica de manera inconsistente. Se utiliza principalmente para los individuos, no para agentes más poderosos como las empresas farmacéuticas que se niegan a compartir datos, patentes y derechos de propiedad en beneficio de todos. Estos agentes pueden incluso aprovecharse de las medidas excepcionales, argumentando que la revisión acelerada de nuevos medicamentos y vacunas debe mantenerse ahora que los procedimientos de revisión más cortos no han repercutido en la fiabilidad y seguridad de los nuevos productos, asumiendo que las condiciones de emergencia pueden prolongarse cuando la pandemia haya terminado. El argumento de la excepcionalidad tampoco se aplica a las personas vulnerables de las residencias de ancianos, las prisiones y las condiciones desfavorecidas que necesitan una protección especial por estar excepcionalmente afectadas por el COVID-19.

En la corriente principialista de la bioética, los principios básicos del discurso ético son el respeto a la autonomía, la beneficencia, la no maleficencia y la justicia. El principio de respeto a la autonomía suele ser el dominante, centrándose en individuos concretos e interpretando la vulnerabilidad de forma individualista. En la pandemia cambió el equilibrio entre estos principios. La salud pública y la ética utilitarista dan prioridad al beneficio y al daño, centrándose en los individuos abstractos como especímenes de un colectivo, e ignorando las cuestiones de vulnerabilidad. El debate ético se desplaza entonces de los intereses individuales a los públicos, pero en ambos marcos se presta menor atención al principio de justicia y al respeto de la dignidad humana. La noción de excepcionalidad define el reto fundamental como un conflicto entre el bien individual y 
el bien común. En lugar de obviar, invertir o desplazar los principios morales, el marco ético que guía la salud pública, la medicina clínica y la investigación debería ampliarse, de modo que se tengan en cuenta más principios.

\section{b) Controlabilidad}

Una de las características más llamativas de la pandemia es la prevalencia de la metáfora de la guerra. Dado que el virus es una amenaza omnipresente para todos, es necesario un esfuerzo común masivo para combatirlo. Sólo hay dos opciones: la victoria o la derrota. Hay que movilizar a toda la sociedad. Todas las esperanzas están puestas en una solución técnica a la crisis del COVID, un arma definitiva que supere los caprichos del comportamiento humano con la simple inyección de una vacuna. Mientras tanto, hay que hacer hincapié en la atención hospitalaria y en el mejor tratamiento posible. En este contexto, sólo hay héroes, víctimas y villanos, y no se puede tolerar la disidencia. Después de que esta guerra mundial termine, hay que hacer esfuerzos denodados para prevenir futuros brotes. La carrera armamentística entre los virus y los seres humanos exige la construcción de un sistema de defensa crítico en todo el mundo, que se tome en serio la guerra contra los virus con capacidades de vigilancia y salud pública, así como normas internacionales que puedan verificarse para garantizar la seguridad mundial, concluidas en un tratado sobre pandemias (28, p. 233 y ss.).

La fuerza impulsora de estos esfuerzos para combatir el virus radica en la creencia en la controlabilidad. Hoy día se pueden identificar rápidamente los virus, secuenciar sus genomas, producir pruebas de diagnóstico y desarrollar vacunas. La propagación del virus puede controlarse con rigurosas medidas de salud pública, con el distanciamiento físico en primer lugar. La controlabilidad, según el filósofo alemán Hartmut Rosa, es una característica de la modernidad. La existencia social moderna se caracteriza por un deseo incesante de hacer que el mundo sea susceptible de ingeniería, predecible,

Medicina y Ética - Enero-Marzo 2022 - Vol. 33 - Núm. 1

https://doi.org/10.36105/mye.2022v33n1.01 
disponible, accesible, desechable (es decir, verfügbar) en todos sus aspectos (29, p. viii). Pero el impulso de controlar separa a los humanos del mundo en el que se encuentran, y considera el mundo como un recurso que hay que explotar, una colección de objetos que hay que dominar, un tesoro de hechos y datos que hay que descubrir y hacer útiles, y un conjunto de obstáculos que hay que superar para avanzar en el florecimiento humano. Todo se ve como un reto. En este contexto, nos encontramos con el mundo, en palabras de Rosa, como un «punto de agresión» (30, pág. 5 y ss.). Ésta es exactamente la perspectiva de la metáfora militar en la pandemia. El virus es un enemigo exterior que hay que controlar y, en última instancia, destruir. Las cuatro dimensiones de la controlabilidad se reflejan en el enfoque de la amenaza viral. En primer lugar, se hace visible, utilizando la ciencia para identificar el virus y las matemáticas para cuantificar el impacto; en segundo lugar, se hace accesible mediante el desarrollo de una prueba de diagnóstico para poder seguir cómo se propaga el virus; en tercer lugar, se hace controlable con la ayuda de medidas de salud pública pero, sobre todo, mediante vacunas; por último, el mundo amenazado se hace controlable haciéndolo útil y más eficiente mediante la vigilancia digital, el trabajo y la educación a distancia y la reestructuración económica.

La dificultad, según Rosa, es que el deseo de control está íntimamente relacionado con la incontrolabilidad. Cuanto más se controla el mundo, más se nos escapa. Por ejemplo, los procesos de globalización y las políticas neoliberales promovieron la idea de que el mundo es un mercado global que se autorregula y que resolverá problemas como la pobreza y el subdesarrollo. Al mismo tiempo, estos procesos y políticas han producido la degradación del medio ambiente y el aumento de la desigualdad que ahora amenazan la seguridad mundial y son casi imposibles de controlar. La paradójica conexión entre control e incontrolabilidad es observable en la pandemia. Existe una fuerte convicción de que la ciencia y la tecnología son los medios óptimos para el control que traerá el alivio. Las herramientas de la ciencia médica proporcionan la mejor 
manera de eliminar la amenaza viral; todos los demás enfoques (simplemente etiquetados como «intervenciones no farmacéuticas») son de uso secundario. Pero una y otra vez, el virus se vuelve incontrolable, ya que los humanos propagan el patógeno. Las ciencias de la virología y la epidemiología son útiles, pero no garantizan que los virus puedan ser controlados, ya que el comportamiento humano no es totalmente predecible y manejable. Incluso cuando se dispone de herramientas eficaces, como las vacunas, los problemas de producción, distribución y despliegue impiden controlar la pandemia. Por tanto, la seguridad sanitaria como objetivo último del control es siempre precaria. Las dos opciones de la metáfora de la guerra (la derrota o la victoria) no permiten una tercera; es decir, que el virus se quede con nosotros y que tengamos que encontrar maneras de vivir con él.

La búsqueda del control y el discurso de la guerra son difíciles de criticar, ya que parecen la forma más racional y eficiente de controlar la pandemia. Los esfuerzos por controlar, gestionar, predecir y calcular la propagación del SARS-CoV-2 reflejan perfectamente la racionalización, burocratización e intelectualización de las sociedades y culturas modernas pero, al mismo tiempo, demuestran lo incontrolable, incierto e imprevisible del mundo de la vida moderna. Cuando la pandemia se prolonga más de lo previsto, y las medidas políticas empiezan a oscilar y son menos consistentes, esta incontrolabilidad se hace más evidente, y hace que la gente sea consciente de lo que se pierde cuando el foco de atención se centra únicamente en los esfuerzos por hacer que el mundo sea controlable. Esta conciencia exige un discurso ético más amplio y profundo.

\section{c) Binaridad}

El COVID-19 ha puesto de manifiesto y agravado las dicotomías y contradicciones existentes dentro de las sociedades y entre ellas. Aunque el SARS-CoV-2 es una amenaza para todos, no todas las personas están «en el mismo barco», ya que algunas están más

Medicina y Ética - Enero-Marzo 2022 - Vol. 33 - Núm. 1

https://doi.org/10.36105/mye.2022v33n1.01 
afectadas que otras. Esto es especialmente cierto, como ya se ha comentado, para las personas que ya eran vulnerables y estaban en desventaja antes de que surgiera la pandemia. El COVID-19 expone y exacerba las desigualdades sanitarias existentes y acentúa la importancia de los determinantes socioeconómicos de la salud. Otra disparidad intensificada en la pandemia es la tensión intergeneracional, que enfrenta a los mayores con los jóvenes. Las personas mayores son las más vulnerables a las graves consecuencias de la infección. Los más jóvenes son los menos afectados, pero se les pide que se queden en casa, que mantengan la distancia física, mientras las escuelas están cerradas. Experimentan la paradoja de la prevención: pueden diseminar el virus sin estar enfermos y con riesgo de efectos graves, pero tienen que cambiar de comportamiento para proteger a los ciudadanos más vulnerables. Los mayores pueden quejarse de que la curva de la pandemia no se aplana debido a la conducta irresponsable de los más jóvenes (que tienen fiestas 'coronavirus', se van de vacaciones y se reúnen en parques públicos sin máscaras y sin distanciamiento físico), mientras ellos tienen que autoaislarse y experimentan una soledad creciente. Por otro lado, las generaciones más jóvenes se quejan de que su vida social se ve restringida por la preocupación por las personas que se encuentran en la fase final de su vida, y de que tienen que esperar más tiempo para volver a la normalidad, ya que se da prioridad a esas personas para la vacunación. Estas tensiones se magnifican a través de algunas políticas, por ejemplo el uso de la edad como criterio de triaje para la asistencia respiratoria. Otros ejemplos son la falta de atención a las residencias de ancianos y de asistencia, donde los residentes de edad avanzada con múltiples comorbilidades no suelen ser trasladados a los hospitales en caso de infección, así como las políticas de inmunidad de rebaño defendidas en Suecia, e inicialmente en el Reino Unido y los Países Bajos. A veces se lanzan propuestas públicas que sugieren que las vidas de algunas personas, especialmente los mayores que ya tuvieron sus «entradas justas», son prescindibles por el bien común, que generalmente se 
interpreta como el libre flujo del mercado y la productividad económica (31).

Las dicotomías y disparidades puestas de manifiesto por la pandemia del COVID-19 revelan el lado oscuro de los enfoques utilitarios en la salud pública. El enfoque utilitario de los sistemas de clasificación, por ejemplo, propone categorías abstractas de priorización y es ciego a las disparidades estructurales de la atención médica, sin tener en cuenta el contexto social y la variabilidad de las necesidades y vulnerabilidades del paciente. Las pautas generalmente no incluyen voces de grupos marginados (32). El uso del argumento de las entradas justas articula aún más las tendencias que ya eran visibles antes de la aparición del coronavirus. Parte de la visión antropológica de los seres humanos como homo economicus son, ante todo, individuos racionales con intereses propios motivados por minimizar los costos y maximizar las ganancias para sí mismos. La vida humana es como una mercancía, un recurso que puede dividirse en partes y acciones. La terminología de las «entradas» supone que la vida es una forma de producir y recoger beneficios. La vida humana no se considera como un todo, en el que todas las etapas tienen un valor y un significado particulares. El concepto de entradas justas también es atractivo porque es cuantitativo. En lugar de mantener un debate ambiguo sobre los principios éticos, sugiere reglas claras que pueden aplicarse y evaluarse de forma coherente porque cuantifica los beneficios (33). Este enfoque considera a los «ancianos» como una categoría homogénea y abstracta que se asocia necesariamente con la vulnerabilidad, la fragilidad, la dependencia y el deterioro, en lugar de considerarlos como personas individuales con características personales, clínicas y sociales distintas, ignorando convenientemente que la mayoría de las personas mayores de 60 años no son débiles, dependientes ni frágiles $(34,35,36)$. Por último, la referencia a las «entradas justas» durante la pandemia acentúa un problema que ya existía. La discriminación por motivos de edad, que a menudo era implícita, se ha convertido ahora en explícita (37). El COVID-19 no sólo ilustra la división en-

Medicina y Ética - Enero-Marzo 2022 - Vol. 33 - Núm. 1

https://doi.org/10.36105/mye.2022v33n1.01 
tre jóvenes y ancianos, sino que articula aún más la discriminación por edad que ya prevalece. La idea de las entradas justas es, por tanto, arbitraria e injusta, e ignora que el enfoque utilitario de la eficiencia debe atemperarse con la preocupación por la igualdad, la vulnerabilidad y la dignidad humana (38).

\section{El marco de la bioética global}

Una vez examinada la forma en que se ha concebido y enmarcado la reflexión ética durante la emergencia de salud pública, el reto es cómo concebir una bioética después del COVID-19 que sea global, no sólo en el sentido de que sea mundial, sino también que abarque, incluya y sea amplia, capaz de ir más allá de las disparidades y dicotomías y de la estrecha imaginación ética que ha prevalecido. Una perspectiva global parte del significado de la relacionalidad para el discurso bioético.

\section{a) La relacionalidad}

La bioética global articula que las personas humanas se caracterizan esencialmente por la relacionalidad. Como conjuntos formados por cuerpo y alma están integrados en comunidades y existen en una red de relaciones con otros seres y con el mundo circundante. Por eso la noción de «esfera» es más apropiada que la de «globo». La relacionalidad es una característica más fundamental que la relación y la conexión. Una persona está continuamente en relaciones, pero a menudo se concibe desde el punto de vista del individuo. La noción de relacionalidad expresa que los individuos no se limitan a conectarse e interactuar entre sí, sino que se pertenecen mutuamente y son mutuamente dependientes, asumiendo la responsabilidad y dando forma a sus vidas juntos. La primera experiencia de los seres humanos es que el mundo se comparte con los demás. Desde esta perspectiva, la autonomía individual se rede- 
fine como «autonomía relacional». La persona humana se constituye a través de encuentros y diálogos con otros seres. El auténtico ser humano es estar-juntos; en palabras de Gabriel Marcel, es estar presente y disponible para los demás (39). La relacionalidad y el estar situado en el mundo implican vulnerabilidad, ya que expone a los seres humanos a otras personas y al mundo circundante. La relacionalidad no es una opción y no podemos hacernos inmunes al mundo.

Es evidente que las relaciones y el parentesco se han vuelto problemáticos en la pandemia. Otras personas se presentan como una amenaza, y las relaciones pueden tener resultados letales, ya que los humanos son los principales vectores del virus. El principal objetivo de las medidas de salud pública es evitar las conexiones e interacciones. El distanciamiento, el enmascaramiento, la prohibición de visitas, el trabajo a distancia y el refugio en casa impiden estar demasiado cerca de otras personas. Por tanto, el COVID-19 parece afectar a la condición antropológica de los seres humanos. Corren el riesgo de ver reducidas su presencia y su disponibilidad, y de perder así lo que es específico de la humanidad. Todas las personas se enfrentan al mismo dilema entre la reclusión o la apertura al mundo, ya que las relaciones se interrumpen, pero no se anula su relacionalidad fundamental. A muchas personas las medidas de salud pública les crean problemas importantes, físicos, porque tienen dificultades para cubrir sus necesidades básicas y mentales porque se sienten solas y deprimidas. Esto hace que la continuación de las políticas de aislamiento sea cada vez más problemática. También explica por qué el término distanciamiento «social» se considera inadecuado, porque aparecieron «burbujas» en las que se permitía la cercanía y la intimidad con, al menos, algunos otros, y surgieron muchas otras formas de interacción y comunicación (40).

\section{b) Intereses individuales frente a intereses comunes}

La oposición entre intereses individuales y comunes que suele dominar en los discursos sobre la pandemia ignora la relacionalidad

Medicina y Ética - Enero-Marzo 2022 - Vol. 33 - Núm. 1

https://doi.org/10.36105/mye.2022v33n1.01 
fundamental de los seres humanos. Los individuos no son entidades aisladas y abstractas, sino seres sociales. Este punto de vista no se acepta en la ideología del individualismo, imperante sobre todo en Occidente, según la cual los seres humanos son independientes y autosuficientes, dueños de su propia vida y de la elección de sus propios valores y, por tanto, individuos únicos, separados y delimitados de otros seres. La implicación normativa de este punto de vista es que el respeto a la autonomía individual significa la no interferencia: las decisiones y acciones individuales deben respetarse siempre que no perjudiquen a otros seres humanos. Desde esta perspectiva, las medidas de salud pública deben apelar en primer lugar a la responsabilidad individual; cualquier interferencia con la libertad personal es problemática, y los encierros y toques de queda son inaceptables. Sin embargo, en la perspectiva de la bioética global, la oposición entre intereses individuales y comunes es falsa, porque el primer tipo de intereses debe reinterpretarse, mientras que el último debe tomarse en serio. Un argumento es que la autonomía personal es una noción relacional. No sólo se ha originado y alimentado en un contexto de dependencia, sino que además se ejerce siempre en interacción con otras personas, dependiendo de las condiciones sociales y culturales (41). Otro argumento es que las preferencias, los valores y las creencias no son meramente individuales, sino que están condicionadas por el contexto social. Las sociedades transmiten los valores a través de las generaciones porque las normas se interiorizan. La capacidad humana de interiorizar las normas significa que las preferencias humanas son socialmente «programables» y el comportamiento humano está guiado por los valores morales de la vida social. Dado que los agentes humanos están socialmente enredados y conectados en red, su conducta no puede explicarse por una racionalidad autocomplaciente dirigida a maximizar los intereses propios, sino por una racionalidad social; es decir, que tiene en cuenta el bienestar de otras personas y las necesidades de la sociedad en general (42). Otro argumento, especialmente expresado en los documentos globales de bioética, es que la 
autonomía está intrínsecamente relacionada con la responsabilidad. Las acciones y decisiones individuales tienen consecuencias sociales, por lo que la autonomía individual y la responsabilidad social no pueden oponerse. La autonomía personal no es abstracta y descontextualizada, sino que tiene repercusiones en otras personas concretas (43).

La pandemia de COVID-19 ilustra claramente que el comportamiento individual afecta al bienestar de la comunidad. El uso generalizado de mascarillas protegerá no sólo al individuo, sino también a otras personas contra una posible infección. Las pruebas identificarán si alguien está infectado, pero es una señal de advertencia de que otros pueden estar en riesgo. El objetivo de la vacunación no es sólo proteger a los individuos, sino a la sociedad en su conjunto. En una emergencia de salud pública, la apelación al interés propio no puede separarse de la preocupación por los intereses de los demás. Las decisiones individuales de adherirse o no a las medidas de salud pública tienen una dimensión inherentemente social. Por lo tanto, las apelaciones a la responsabilidad individual no serán suficientes sin articular la responsabilidad social y sin crear las condiciones sociales, políticas y económicas para el ejercicio de la autonomía responsable. Que las políticas individualistas fracasan sin esta dimensión de responsabilidad social es evidente en los debates relativos a la cuarentena, el aislamiento, el encierro y el distanciamiento, en los que se argumenta que se violan la dignidad y los derechos humanos. En estos debates, la dignidad y los derechos se consideran con frecuencia nociones que se aplican estrictamente a los individuos. La dignidad humana se considera una construcción teórica y abstracta, una cualidad intrínseca que se aplica por igual a todos los seres humanos. No depende de características o condiciones humanas como la edad, el sexo o la enfermedad. No puede ser mermada o arrebatada por ninguna autoridad o sistema político, ni ignorada en condiciones de emergencia. La dignidad no depende de que se reconozca o se respete, ya que sigue existiendo incluso en las circunstancias más funestas o crueles. Sin embargo, esto es

Medicina y Ética - Enero-Marzo 2022 - Vol. 33 - Núm. 1

https://doi.org/10.36105/mye.2022v33n1.01 
sólo una parte de la historia de la dignidad humana. También es un fenómeno práctico, una experiencia vivida. Se refiere a la forma en que los seres humanos se comportan y son tratados. La dignidad humana es, pues, una cualidad relacional. Desde esta perspectiva, la dignidad puede no respetarse, perderse o destruirse. En determinadas situaciones y prácticas, los seres humanos experimentan amenazas a su dignidad y se enfrentan a condiciones indignas (44). Los derechos humanos son objeto de debates similares. A veces se interpretan como derechos de los individuos, haciendo especial hincapié en la no injerencia para proteger a los individuos frente al Estado, y considerando así los derechos civiles y políticos como más importantes que los derechos sociales y económicos. Desde este punto de vista, el individualismo moral está en el centro del lenguaje de los derechos humanos como discurso de empoderamiento individual. Sin embargo, todos los derechos humanos son interdependientes. Los derechos civiles y políticos no pueden ejercerse si no se proporcionan las condiciones básicas para la existencia humana, expresadas por los derechos sociales y económicos. Las personas individuales sólo pueden ser empoderadas dentro de un contexto relacional con los demás. El derecho a la salud ilustra que la dimensión individual de los derechos humanos está conectada con una dimensión de solidaridad y de bien colectivo: si no existen las condiciones adecuadas, como el acceso a la atención sanitaria y a unos servicios sanitarios de calidad, las personas no pueden disfrutar de su derecho a la salud. Al igual que la dignidad humana, los derechos humanos se basan en el reconocimiento de que los seres humanos comparten necesidades y vulnerabilidades fundamentales (45, p. 113 y ss.).

Los argumentos anteriores se aplican a otra oposición que se ha intensificado durante la pandemia: el nacionalismo frente al globalismo. En condiciones de emergencia, los intereses nacionales dominan el enfoque del COVID-19. Los países se preocupan en primer lugar por sus propios ciudadanos, e intentan hacerse con la mayor cantidad posible de equipos de protección, máscaras y ma- 
teriales de prueba, a menudo compitiendo entre sí y sin tener en cuenta las necesidades de otras naciones menos poderosas y económicamente más débiles. Los países de altos ingresos encargan y compran las vacunas en enormes cantidades, dejando a los demás países al final de la cola. La Organización Mundial de la Salud y los actores internacionales han argumentado en múltiples ocasiones que las políticas nacionales no serán suficientes para controlar la pandemia mientras falte un enfoque global (46). Los argumentos son familiares: el nacionalismo perjudicará a todo el mundo y es contraproducente porque todas las personas están conectadas. El virus no reconoce fronteras ni naciones, sino que afecta a la población mundial y requiere soluciones globales. Aunque el virus pueda ser eliminado en un país, el comercio y los viajes seguirán afectados, las economías no se recuperarán y la estabilidad y la prosperidad no volverán mientras el virus siga arrasando en todo el mundo. Por lo tanto, a cada nación le interesa participar en los esfuerzos globales para hacer frente al COVID-19 (47). Los enfoques nacionalistas no sólo son estrechos de miras, sino también contraproducentes en el largo plazo, cuando el virus sigue diseminándose y mutando en algunas partes del mundo.

\section{c) Solidaridad}

En el contexto de la salud pública, la solidaridad es desde hace tiempo un valor ético fundamental. Dado que los sistemas sanitarios son interdependientes y las amenazas de enfermedades son globales, es necesaria la colaboración entre las instituciones sanitarias a nivel nacional, regional y mundial, lo que requiere una comunicación abierta, el intercambio de información y la coordinación de las respuestas políticas. En la pandemia del COVID-19, los organismos internacionales han hecho hincapié en repetidas ocasiones en la solidaridad como concepto central. Los comités éticos de la UNESCO califican de «deber ético construir la solidaridad y la cooperación» (48, p. 4), mientras que los asesores éticos de la Unión

Medicina y Ética - Enero-Marzo 2022 - Vol. 33 - Núm. 1

https://doi.org/10.36105/mye.2022v33n1.01 
Europea se refieren a la solidaridad como «una vacuna social» contra la indiferencia y la exclusión (49, p. 4). Sorprendentemente, el Grupo de Trabajo sobre Ética y COVID-19 de la OMS enumera la solidaridad como el primer principio ético a aplicar (50). La Comisión COVID-19 del Vaticano afirma que el principio de solidaridad debe ser la base de cualquier intervención específica y concreta en respuesta a la pandemia, lo que implica que las vacunas deben estar disponibles y ser accesibles para todos (51).

La solidaridad suele explicarse con referencias a los mismos fundamentos que la noción de relacionalidad: se basa en el reconocimiento mutuo de que los seres humanos comparten las mismas necesidades, de que su destino está interconectado, de que las vulnerabilidades son características humanas cruciales, pero no se experimentan por igual, y de que el bienestar de todos los ciudadanos del mundo debería ser la principal preocupación de las políticas globales. Sin embargo, lo típico de la solidaridad no son sólo estas explicaciones teóricas, sino sus implicaciones prácticas. Más que un sentimiento de conexión y de intenciones de actuar, la solidaridad se manifiesta en el apoyo a una causa específica y en la acción común, reconociendo que las capacidades para hacer frente a las amenazas globales son desiguales. Requiere que la comprensión de la interdependencia y la voluntad de ayudar a los demás se traduzcan en una acción pública, demostrando que los intereses propios están subordinados a los de los demás. Dicha acción puede estar motivada por el interés propio mutuo, especialmente en una pandemia en la que a todos les interesa reducir y eliminar las infecciones, pero el núcleo de la solidaridad es la preocupación moral por los demás, el compromiso desinteresado con el otro más que la expectativa de un beneficio unilateral. No se manifiesta porque otras personas sean una amenaza para nuestra salud, sino porque la salud mundial está conectada y es interdependiente. La solidaridad difiere de la caridad, la ayuda y la generosidad; significa mutualidad, una relación simétrica entre iguales e implica, por tanto, inclusión y cooperación (52). 
Aunque hay muchos ejemplos de solidaridad a nivel interpersonal e institucional, la ausencia de solidaridad a nivel mundial durante la pandemia es inconcebible. Esto no sorprende, ya que las condiciones para la solidaridad se han erosionado en las últimas décadas. Las políticas globales y la cooperación internacional se han centrado principalmente en los intereses económicos. Por ejemplo, en la Unión Europea, la protección de la salud humana no ha recibido prioridad, ya que la organización y prestación de servicios sanitarios y atención médica es responsabilidad principal de cada uno de los Estados miembros. Instituciones mundiales como la Organización Mundial de la Salud se han visto sistemáticamente debilitadas por los recortes presupuestarios y los intentos de deslegitimar su labor (53). En la mayoría de los países se han reducido las infraestructuras sanitarias públicas y la salud se considera ante todo una responsabilidad individual y no colectiva. El principal motor de la cooperación es la ideología neoliberal del libre mercado, que hace hincapié en la competencia, el libre comercio y la comercialización de todos los aspectos de la vida humana. En esta ideología, la interferencia del gobierno debe reducirse al máximo, y se fomenta la desregulación, la privatización, la reducción de impuestos y del gasto público. En esta filosofía del egoísmo racional, las sociedades son meras colecciones de individuos, y la solidaridad se rechaza o se considera un valor superfluo. Los mismos procesos han socavado la solidaridad dentro de las sociedades. El dominio del individualismo y la visión de la persona humana como homo economicus han disminuido la experiencia de los seres humanos de que están integrados en comunidades, culturas y entornos, y la conciencia de que su destino está conectado con otros lejanos como ciudadanos del mundo. Dado que la solidaridad no puede imponerse unilateralmente o de arriba abajo, no surgirá en estas condiciones (54).

Este análisis aclara que el fracaso de la solidaridad global es el resultado de políticas que promueven valores específicos a expensas de otros. La pandemia del COVID-19 demuestra las insuficien-

Medicina y Ética - Enero-Marzo 2022 - Vol. 33 - Núm. 1

https://doi.org/10.36105/mye.2022v33n1.01 
cias de estas políticas. Las infraestructuras de salud pública de la mayoría de los países se muestran incapaces de hacer frente al virus. Las apelaciones a la responsabilidad individual no consiguen por sí solas controlar su transmisión. Son necesarias intervenciones gubernamentales masivas para apoyar el sistema sanitario, la economía y todos los sectores de la vida social. El mercado libre no es capaz de producir cantidades suficientes de equipos de protección, medicamentos y vacunas sin un apoyo público sustancial. Al mismo tiempo, la bioética dominante, basada en el lenguaje de la autonomía, los intereses, la utilidad, la eficiencia y los derechos negativos, presenta una visión miope de las preocupaciones éticas relevantes. $\mathrm{Al}$ partir del punto de vista del individuo autónomo, no puede reconocer la conectividad de los seres humanos ni las dimensiones globales de la pandemia y, por tanto, la necesidad de respuestas globales. Después del COVID-19, la bioética no puede seguir asumiendo que la autonomía es el principio ético dominante; debe reconocer que tomarse en serio la relacionalidad humana implica potenciar y abrazar las condiciones sociales y estructurales que hacen posible la solidaridad.

\section{Conclusión}

La importancia de la salud mundial, acentuada por el COVID-19, subraya la necesidad de un discurso más amplio de la bioética mundial. Los análisis éticos dominantes suelen orientarse hacia la gestión de la enfermedad, los enfoques tecnocráticos y el tratamiento individual, en lugar de prestar atención a las condiciones en las que surgen y se expanden las enfermedades. Estas tendencias se ven reforzadas durante la emergencia de la pandemia, haciendo hincapié en la excepcionalidad, la controlabilidad y la binaridad, estructurando y enmarcando así las consideraciones éticas de forma específica y estrecha, relegando las preocupaciones por la vulnera- 
bilidad, la dignidad humana, la desigualdad, la cooperación y la solidaridad a un nivel inferior de urgencia e interés. La pandemia del COVID-19 ilustra que otra forma de pensar y trabajar es útil para aclarar las dimensiones éticas de la vida actual. El punto de partida del argumento es la relacionalidad básica de los seres humanos. No se trata sólo de la visión de que las personas humanas están conectadas con otros seres y con el mundo circundante, sino de la perspectiva filosófica de que ser humano significa estar-juntos. Las personas sólo pueden existir y florecer porque comparten el mundo, pertenecen juntas, están presentes y disponibles las unas para las otras. Esta relacionalidad básica tiene un significado ético. Estar situado dentro de las relaciones y comprometerse con otros seres significa vulnerabilidad. La apertura al mundo y la dependencia mutua son necesarias para que las personas crezcan, se desarrollen y florezcan, pero también las expone a posibles daños y perjuicios. Los seres humanos no pueden inmunizarse ante el mundo, ya que entonces perderían lo que les caracteriza como seres humanos. El discurso ético es una forma de mitigar y remediar la vulnerabilidad. Nos anima a cambiar de perspectiva y a imaginarnos en la posición de otras personas que tienen las mismas necesidades, deseos y sentimientos que nosotros. Expresa que cuando compartimos el mundo, debemos reconocer a los demás que tienen vidas que vivir, y debemos tratar sus intereses como iguales a los nuestros.

El COVID-19 ha revivido los recuerdos colectivos del pasado, en su mayoría olvidados, y en especial los de la pandemia de influenza de hace un siglo. Los seres humanos se dan cuenta ahora de que viven en una era pandémica que comenzó en 1918, y que la idea de que las enfermedades infecciosas pueden controlarse es falsa. Más que otras catástrofes, el COVID-19 ha afectado a todas las dimensiones de la vida cotidiana de todos los pueblos del mundo. La propagación del SARS-CoV-2 hace visible y tangible para todos que los seres humanos son interdependientes, ilustrando que la globalización es un fenómeno de salud y enfermedad, y no simplemente

Medicina y Ética - Enero-Marzo 2022 - Vol. 33 - Núm. 1

https://doi.org/10.36105/mye.2022v33n1.01 
de comercio, viajes y finanzas. La globalización ya no es un conjunto abstracto de procesos, sino una experiencia de vulnerabilidad mutua y personal. Todo el mundo se enfrenta a la misma amenaza, y el conocimiento científico del virus es el mismo para todos y se comparte rápidamente en todo el mundo. Sin embargo, las respuestas a la pandemia son diversas y heterogéneas. Algunos países han gestionado el impacto del virus de forma rápida y eficaz, cuando de hecho muchos otros han cometido errores, retrasos y vacilaciones en la aplicación de medidas de salud pública. Una de las razones por las que las estrategias globales ante la pandemia difieren tiene que ver con los valores (por ejemplo, la responsabilidad individual frente a la social; el cumplimiento voluntario y el autocontrol frente a la aplicación estatal y el control externo; las libertades individuales frente a la solidaridad). Que el COVID-19 tiene relevancia ética se manifiesta además en las desigualdades sociales que ha revelado y agravado. Pone al descubierto las disparidades socioeconómicas y raciales en materia de salud y asistencia sanitaria, así como los privilegios de las personas que tienen casas que albergar y trabajos que pueden realizar a distancia. Las tendencias a la discriminación de las personas mayores y discapacitadas se magnifican, y la estigmatización y la búsqueda de chivos expiatorios no son cosa del pasado. La pandemia también revela la falta de preparación de la mayoría de los países y la insuficiencia de las infraestructuras de salud pública. Además, aclara que el orden económico promovido por las políticas neoliberales de la globalización en las últimas décadas ha conducido al empobrecimiento moral del mundo de la vida social y a la multiplicación de las experiencias de injusticia, especialmente de humillación, falta de respeto y desigualdad.

Por estas razones, la pandemia es una oportunidad para repensar la globalización, la gobernanza global, la salud pública y la asistencia sanitaria con una nueva apreciación del bien común y del papel de los gobiernos en la protección de los ciudadanos, con más 
énfasis en la resiliencia que en la eficiencia. Si la bioética como esfuerzo social y global moviliza la imaginación moral para expandir el alcance de la preocupación moral mediante la aplicación de la capacidad humana de empatizar, contribuye de manera crucial a mejorar la vida social y la civilización.

\section{Referencias bibilográficas}

1. Ho A, Dascalu I. Global disparity and solidarity in a pandemic. Hastings Center Report. 2020; 50(3): 65-67. https://doi.org/10.1002/hast.1138

2. Fins JJ. Covid-19 makes clear that bioethics must confront health disparities. The Hastings Center. 9 de julio de 2020. https://www.thehastingscenter.org/covid19-makes-clear-that-bioethics-must-confront-health-disparities/

3. Venkatapuram S. Covid-19 and the global ethics freefall. The Hastings Center. 19 de marzo de 2020. https://www.thehastingscenter.org/covid-19-and-the-globalethics-freefall/

4. Cohen J. Individual freedom or public health? A false choice in the Covid era. The Hastings Center. 9 de junio de 2020. https://www.thehastingscenter.org/individual-freedom-or-public-health-a-false-choice-in-the-covid-era/

5. Lewis J, Schuklenk U. Bioethics met its Covid-19 Waterloo: The doctor knows best again. Bioethics. 2021; 35: 3-5. https://doi.org/10.1111/bioe.12840

6. Chadwick R. Covid-19 and the possibility of solidarity. Bioethics. 2020; 34(7): 637. https://doi.org/10.1111/bioe.12813

7. Klugman $\mathrm{C}$. The cult of autonomy and why bioethics needs to become more communal. Bioethics. Net. 24 de septiembre de 2020. http://www.bioethics.net/2020/ 09/the-cult-of-autonomy-and-why-bioethics-needs-to-become-more-communal/ 8. Wolf SM. What has Covid-19 exposed in Bioethics? Four Myths. Hastings Center Report. 2021; 51(3): 3-4. https://doi.org/10.1002/hast.1254

9. Ravitsky V. Post-Covid bioethics. The Hastings Center. 20 de mayo de 2020. https://www.thehastingscenter.org/post-covid-bioethics/

10. Gostin LO, Moon S, Meier BM. Reimagining global health governance in the age of Covid-19. American Journal of Public Health. 2020; 110(11): 1615-1619. https://doi.org/10.2105/AJPH.2020.305933

11. Chadwick R. Covid-19 and the possibility of solidarity. Bioethics. 2020; 34(7): 637. https://doi.org/10.1111/bioe.12813

12. Martins AA. Global bioethics in a pandemic: A dialogical approach. Health Care Ethics USA. 2021. https://www.chausa.org/publications/health-care-ethicsusa/article/winter-2021/global-bioethics-in-a-pandemic-a-dialogical-approach 13. Heilinger J, Venkatapuram S, Voss M and Wild V. Bringing ethics into the global coronavirus response. The Hastings Center. 22 de junio de 2020. https:// www.thehastingscenter.org/bringing-ethics-into-the-global-coronavirus-response/

Medicina y Ética - Enero-Marzo 2022 - Vol. 33 - Núm. 1

https://doi.org/10.36105/mye.2022v33n1.01 
14. Potter VR. Bioethics: Bridge to the future. Englewood Cliffs: Prentice Hall, 1971. 15. Ingold T. 2000. Globes and spheres. The topology of environmentalism. In Ingold T, editor. The perception of the environment. Essays on livelihood, dwelling and skill. London and New York: Routledge. 2000; 209-218.

16. Cha I. The mundialization of home in the age of globalization. Towards a transcultural ethics. Mûnchen: LIT Verlag; 2012.

17. Hawkins D. Differential occupational risk for COVID19 and other infection exposure according to race and ethnicity. American Journal of Industrial Medicine. 2020; 63(9): 817-820. https://doi.org/10.1002/ajim.23145

18. Kiaghadi A, Rifai HS, Liaw W. Assessing COVID-19 risk, vulnerability and infection prevalence in communities. PLOS ONE. 2020; 15(10): e0241166.

https://doi.org/10.1371/journal.pone.0241166

19. Cleveland Manchanda E, Couillard C, Sivashanker K. Inequity in crisis standards of care. New England Journal of Medicine. 2020; 383(4): e16.

https://doi.org/10.1056/NEJMp2011359

20. Horton R. The COVID-19 catastrophe. What's gone wrong and how to stop it happening again. Cambridge: Polity, 2020.

21. Chik H, Baptista E. Chile CovID-19 vaccination drive adds to Sinovac efficacy data. South China Morning Post. 9 de abrirl de 2021. https://www.scmp.com/news/ china/science/article/3128886/chile-covid-19-vaccination-drive-adds-sinovac-efficacy-data

22. WHO (World Health Organization). Malaria. Key facts, 2021.

23. WHO (World Health Organization). Tuberculosis. Key facts, 2020.

24. WHO (World Health Organization). Dengue and severe dengue. Geneva: WHO, 2020.

25. WHO (World Health Organization). Ten threats to global health in 2019.

https://www.who.int/news-room/spotlight/ten-threats-to-global-health-in-2019.

26. Ryan F. Virusphere. Ebola, AIDS, influenza and the hidden world of the virus. London: William Collins, 2019.

27. Honigsbaum M. The pandemic century. One hundred years of panic, hysteria, and hubris. New York: W. W. Norton \& Company, 2020.

28. Mackenzie D. WHO-19. The pandemic that never should have happened, and how to stop it. London: The Bridge Street Press, 2020.

29. Rosa $\mathrm{H}$. The uncontrollability of the world. Cambridge: Polity Press, 2020.

30. Rosa H. The uncontrollability of the world. Cambridge: Polity Press, 2020.

31. Symons $X$. Should we sacrifice older people to save the economy? BioEdge. 28 de marzo de 2020. https://www.bioedge.org/bioethics/should-we-sacrifice-older-people-to-save-the-economy/13377

32. Childs BH, Vearrier I. A journal of the COVID-19 (plague) year. HEC Forum. 2021; 33: 1-6. https://doi.org/10.1007/s10730-021-09448-6

33. Williams A. Intergenerational equity: An exploration of the 'fair innings' argument. Health Economics. 1997; 6: 117-132. https://doi.org/10.1002/(SICI)10991050(199703)6:2<117::AID-HEC256>3.0.CO;2-B 
34. Fisher A. Fair innings? Against healthcare rationing in favour of the young over the elderly. Studies in Christian Ethics. 2013; 26(4): 431-450.

https://doi.org/10.1177/0953946813492918

35. Bramstedt KA. Age-based health care allocation as a wedge separating the person from the patient and commodifying medicine. Reviews in Clinical Gerontology. 2001; 11: 185-188. https://doi.org/10.1017/S0959259801011297

36. De Medeiros K. A covID-19 side effect: Virulent resurgence of ageism. The Hastings Center. 14 de mayo de 2020. https://www.thehastingscenter.org/a-covid19-side-effect-virulent-resurgence-of-ageism/

37. Peisah C, Byrnes A, Doron I, Dark M, Quinn G. Advocacy for the human rights of older people in the COVID pandemic and beyond: a call to mental health professionals. International Psychogeriatrics. 2020; 32(10):1199-1204.

https://doi.org/10.1017/S1041610220001076

38. Kuylen MNI, Kim SY, Keene AR, Owen GS. Should age matter in CoVID-19 triage? A deliberative study. Journal of Medical Ethics. 2021; 47: 291-295.

https://doi.org/10.1136/medethics-2020-107071

39. Marcel, G. Homo viator. Introduction to a metaphysic of hope. New York: Harper \& Row, 1962.

40. Kaminsky C. 2020. Normality «ex post»: social conditions of moral responsibility. In Woesler M, Sass HM, editors. Medicine and ethics in times of corona. Zürich: LIT Verlag. 2020; 63-74.

41. Mackenzie C, Stoljar N. Relational autonomy: feminist perspectives on autonomy, agency, and the social self. New York: Oxford University Press, 2000.

42. Gintis H. Individuality and entanglement: The moral and materials bases of social life. Princeton and Oxford: Princeton University Press, 2017.

https://doi.org/10.1515/9781400883165

43. WeCope (World Emergency CovID-19 Pandemic Ethics Committee). Statement on individual autonomy and social responsibility within a public health emergency. In Woesler M, Sass HM, Editores. Medicine and ethics in times of corona. Zürich: LIT Verlag. 2020; 419-425.

44. Bieri P. Human dignity: A way of living. Cambridge: Polity Press, 2017.

45. Ten Have H. Global bioethics. An introduction. London and New York: Routledge; 2016. https://doi.org/10.4324/9781315648378

46. WHO (World Health Organization). WHO Director-General's statement on Tanzania and CoVID-19. 2021. https://www.who.int/news/item/20-02-2021-who-director-general-s-statement-on-tanzania-and-covid-19

47. Eurasia Group. Ending the COVID-19 pandemic: The need for a global approach. November 25, 2020. https://www.who.int/docs/default-source/coronaviruse/act-accelerator/2020-summary-analysis-of-ten-donor-countries-11_26_2020-v2.pdf 48. UNESCO. Statement on COVID-19: Ethical considerations from a global perspective. Paris: UNESCO, 2020. https://unesdoc.unesco.org/ark:/48223/pf0000373115. 49. European Group on Ethics in Science and New Technologies. Statement on European solidarity and the protection of fundamental rights in the Covid-19 pan-

Medicina y Ética - Enero-Marzo 2022 - Vol. 33 - Núm. 1 
demic. April 2, 2020. https://ec.europa.eu/info/sites/default/files/research_and_innovation/ege/ec_rtd_ege-statement-covid-19.pdf 50. Dawson A, Emanuel EJ, Parker M, Smith MJ and Voo TC. Key ethical concepts and their application to Covid-19 research. Public Health Ethics. 2020; 13(2): 127-132. https://doi.org/10.1093/phe/phaa017

51. Pontifical Academy for Life. Vaccine for all. 20 points for a fairer and healthier world. 29 de diciembre de 2020. https://press.vatican.va/content/salastampa/it/boIlettino/pubblico/2020/12/29/0697/01628.html\#notaing

52. Jennings $B$, Dawson A. Solidarity in the moral imagination of bioethics. Hastings Center Report. 2015; 45(5): 31-38. https://doi.org/10.1002/hast.490

53. Brown G, Susskind D. International cooperation during the Covid-19 pandemic. Oxford Review of Economic Policy. 2020; 36(S1): S64-S76.

https://doi.org/10.1093/oxrep/graa025

54. West-Oram PGN, Buyx A. Global health solidarity. Public Health Ethics. 2017; 10(2): 212-224. https://doi.org/10.1093/phe/phw021

Esta obra está bajo licencia internacional Creative Commons Reconocimiento-NoComercial-Compartirlgual 4.0.

\section{(c) (i) (5) (2)}

